\title{
BLOODLESS MANAGEMENT OF ANAEMIC HIV - INFECTED PATIENTS IN SOUTH- SOUTH, NIGERIA.
}

\section{OZINKO MBA O., ${ }^{1 *}$ BASSEY GRACE I, ${ }^{2}$ OZINKO ASSEM M. ${ }^{3}$}

${ }^{1}$ Division of burns and plastic surgery, department of surgery, university of calabar teaching hospital, calabar, nigeria Email: ozinkomba@yahoo.com, phone no: +2348-0634o6514

${ }^{2}$ division of burns and plastic surgery, department of surgery, university of calabar teaching hospital, calabar.

${ }^{3}$ asynko specialist clinic, calabar, nigeria

\section{*Corresponding author:}

Email: ozinkomba@yahoo.com, phone no: +2348-0634o6514

\begin{abstract}
: -
This is a prospective study that aimed at comparing patients' morbidity and mortality among severely anaemic HIVpatients who were transfused and those who were no transfused. Anaemia is a common presentation among patients with human immunodeficiency virus infection. We treated 13 patients who had packed cell volume $\geq 20 \%$ and were randomized into two groups: group $A$ had blood transfusion while group B did not. Other treatments such as haematinics, antihelminthics, antibiotics, treatment of opportunistic infections, no infusion and balanced nutrition were given to them. The survival rate was higher among those who did not receive blood transfusion while those who were transfused had higher mortality rate. The study concluded that bloodless management of severely anaemic HIV-patients with PCV $\geq$ $20 \%$ without blood transfusion had higher survival rate than those who were transfused.
\end{abstract}

Key words: Anaemia, Human Immunodeficiency Virus (HIV), Blood transfusion, Bloodless Medicine and Surgery $(B M S)$. 


\section{INTRODUCTION}

Anaemia is a common presentation among patients with severe human immunodeficiency virus (HIV) infection or acquired immunodeficiency syndrome (AIDS). It is a well-known fact that retroviral disease lowers the body immunity and blood transfusion has documented evidence of immune suppression [Volberg 2004]. There are other inherent risks associated with blood transfusion which are known, and some could not well be explained due to inability to isolate all the reactive products of blood and test them before transfusion [Herbert,1999]

With the advent of deadly blood transfusion transmissible infections such as hepatitis B, C and D, Ebola virus and HIV infection, many members of the public are increasingly advocating for Bloodless Medicine and Surgery. The pathogenesis of anaemia in human immunodeficiency syndrome is multifactorial. It could be due to HIV infection, chronic disease due to opportunistic infection, bone marrow suppression and haemolytic anaemia caused by oxidant drugs [Blumberg [1994]. At the onset of HIV infection in Southern Nigeria, the need for managing the anaemia with blood transfusion was the gold standard, followed by the treatment of the opportunistic infections. In the recent past, the thinking of some clinicians towards blood transfusion in these patients has been discouraged. It was observed that the transfusion of allogenic blood to these patients do not give them any hope of survival rather they die. It is on this premise that bloodless management of medicine and surgery is receiving greater acceptance by clinicians.

\section{PATIENTS AND METHODS}

This is a randomized prospective study which started in May, 2018 to August, 2019. Patients were drawn from Division of Burns and Plastic Surgery of the University of Calabar Teaching Hospital, Calabar and Heritage Specialist Clinic, Calabar. The patients were recruited into the study, with age range of 28-51 years, with a mean age of 39.8 \pm 3 years. The inclusion criteria were those patients with packed cell volume $\geq 20 \%$ and were not going in for emergency surgery. The exclusion criteria were those patients with packed cell volume $\leq 20 \%$, patient having ongoing blood loss or were going in for emergency surgery and those on anticancer treatment. The patients were divided into two groups: group A patients were transfused with two to three units of blood within their hospital stay while group B were not transfused. Their packed cell volumes were evaluated forth nightly. The two groups were placed on antibiotics for the treatment of opportunistic infections. They had tablet Diflucan 50mg daily for one- two weeks. The patients with cough, either productive of sputum or not and those with sputum were tested for mycobacterium tuberculosis by using Zeil Nelson stain and Gene Xpert, either productive or not were placed on tablet isoniazid 300mg daily and co-trimoxazole $960 \mathrm{mg}$ daily for pneumocystis carinii for 3 months. Their co-morbid conditions such as ulcers, diabetes mellitus, hypertension, etc were equally treated while their elective surgical conditions were deferred until their general conditions had improved. A routine of treating all the patients with artemisinin combination therapy was used as malaria is a common cause of anaemia in them. They were placed on haematinics e.g folic acid 5mg, ferrous sulphate 100-200mg thrice daily, tab vitamin C 400-1000mg daily, vitamin B complex 3-6tabs daily and injection vitamin B12 $200 \mathrm{mcg}$ daily were administered. Nutritional optimization with increased protein- calorie diets were given. Patients were placed on 2-3 eggs daily for 1-2 weeks, complan, fortified pap with soya beans and crayfish were also given. Dark leafy green vegetables (pumkin leaf, amaranthus. lettuce), local fruits and adequate oral fluid intake were given. No intravenous infusion was administered. In some chronically ill patients, nasogastric tube was passed to ensure adequate delivery of food. Patients were placed on antiretroviral drugs from the 2nd-3rd week on admission based on their clinical status. The antiretroviral agent used was a combination of Dolutegravir/Lamivudine / Tenofovir Disoproxil Fumarate tablet $(50 \mathrm{mg} / 300 \mathrm{mg} / 300 \mathrm{mg}$ strength) which had minimal adverse reactions.

Patients' clinical states were evaluated twice weekly on ward rounds for recovery of symptoms such as breathlessness, fatigue, diarrhea, cough, itching, etc. Their haematocrit tests were also evaluated every two weeks. Weekly weighing of the patients was also done.

Patients with surgical conditions were operated after they were fully optimized and haematocrit values are above $30 \%$. Blood conservation techniques were adopted. Meticulous surgical technique which reduced blood loss was instituted. Post-operative hamatocrit levels were also assessed. In major surgeries, autologous blood transfusion was done and patient continued with haematinics. Patients were discharged when they had improved and were also followed up in the clinic. The findings were entered into excel spreadsheet and the analysis was done with SPSS version 18.0. using simple regression technique.

\section{RESULT:}

A total of 13-patients with severe anaemia in HIV patients were recruited into the study. The age range was from 28-51 year with mean age of 39.8year \pm 3 years. The male female ratio was 1.6:1. Their packed cell volume ranges between $12 \%$ and $20 \%$, with a mean value of $16.9 \% \pm 0.3 \%$. The haematocrit values on discharge or dead ranged between 15 and $29.2 \%$, with mean value of $24.1 \%$. The hospital stay ranged from 3-8weeks, with mean stay of 5 weeks. The overall survival rate was $61.5 \%(n=8)$ while the mortality rate was $38.5 \%(n=5)$. The number of patients who survived after blood transfusion were $42.9 \%(n=3)$ while those who died were $57.1 \%(n=4)$. The number of patients who survived without blood transfusion was $83.3 \%(n=5)$ while those who did not receive transfusion and later died was $16.5 \%(n=1)$. The study has shown that the survival rate was better in Group B that was not transfused than Group A who received transfusion in severely anaemic patients with retroviral disease as shown in table 1 below. 
TABLE 1: Comparison of the treatment Outcome of Anaemic HIV-infected Patients who were transfused[BT] and others who were not[NBT].

\begin{tabular}{|l|l|l|l|l|l|l|}
\hline $\begin{array}{l}\text { S } \\
\text { N }\end{array}$ & $\begin{array}{l}\text { SE } \\
\text { X }\end{array}$ & $\begin{array}{l}\text { AGE } \\
(\text { YRS } \\
)\end{array}$ & $\begin{array}{l}\text { PCV } \\
(\%) \text { ON } \\
\text { ADMISSIO } \\
\text { N }\end{array}$ & $\begin{array}{l}\text { TRANSFUSIO } \\
\text { N }\end{array}$ & $\begin{array}{l}\text { PCV } \\
\text { DEAD/DICHARG } \\
\text { EN }\end{array}$ & $\begin{array}{l}\text { TREATMEN } \\
\text { T } \\
\text { OUTCOME }\end{array}$ \\
\hline 1 & F & 29 & 20 & NBT & 28 & Alive \\
\hline 2 & M & 38 & 18 & BT & 12.8 & Dead \\
\hline 3 & M & 47 & 15 & NBT & 19.4 & Dead \\
\hline 4 & F & 50 & 16 & NBT & 25.1 & Alive \\
\hline 5 & F & 35 & 12 & BT & 15 & Dead \\
\hline 6 & M & 42 & 17.5 & BT & 29 & Alive \\
\hline 7 & M & 49 & 20 & NBT & 29.2 & Alive \\
\hline 8 & F & 28 & 18.6 & BT & 27.4 & Alive \\
\hline 9 & F & 43 & 14.5 & NBT & 25.8 & Alive \\
\hline 10 & M & 51 & 19.8 & BT & 27.2 & Dead \\
\hline 11 & M & 44 & 16.4 & NBT & 28.5 & Alive \\
\hline 12 & F & 30 & 12.8 & BT & 26.8 & Alive \\
\hline 13 & M & 36 & 19.5 & BT & 29.1 & \\
\hline
\end{tabular}

BT= Blood Transfusion, NBT= No Blood Transfusion

\section{DISCUSSION}

There is gradual reduction in Human Immunodeficiency Virus pandemic in African following its prevention and accessibility to antiretroviral drugs. The presentation of these patients with anaemia, especially with malaria which is endemic, makes it even more worrisome. A study was conducted by Lum [2016] to assess the impact of human immunodeficiency virus and plasmodium falciparium genetic diversity on anaemia in HIVpatients attending their health facility which showed more HIV-patients were malaria positive(34.77\%), anaemia(31.96\%) compared to those in malaria mono-infection i.e $16.5 \%$ and $3.03 \%$ respectively. The study concluded that HIV could predispose patients to more malaria and anaemia compared to the general population. Thus, the researcher treated all the patients for malaria using the artemesinin combination therapy. A study by Bhusal and associates [2016] concluded that there is high prevalence of anaemia, and the severity of immunodeficiency correlates with the degree of anaemia. Studies have also shown that there is an association between anaemia with HIV, decreased survival and increased disease progression in patients with HIV infection [2004]. The median duration of survival was significantly shorter in persons with anaemia (defined as haemoglobin level of $<10 \mathrm{~g} / \mathrm{dl}$ ) than in those without anaemia, regardless of baseline CD4 Count[2002].

In recent years, a more conservative approach to blood transfusion has begun to become the rule rather than the exception in clinical outcome research demonstrating that patients receiving traditional allogenic transfusions have dramatically higher rates of morbidity and mortality than do similar patients not receiving transfusion. [ 2002]. Studies have reported reduced infections and cancer recurrences in patients receiving autologous transfusion compared with allogenic transfusion. [Sullivan, 2002; Volberding, 2002].

Attempt at reducing or preventing the dangers of allogenic blood transfusion, the following steps could be adopted: (1) entirely avoiding blood transfusion,(2) avoiding or reducing allogenic transfusion by use of autologous transfusion, haemodilution and blood salvage and(3) finally, administering only leucocyte reduced red cell transfusion[2018].

Recent reviews of transfusion immunology often fail to address this subject because of its contentious nature, perhaps, a reluctance to challenge long-standing clinical practice that have been in use for most of a century.

Based on the aforementioned reasons, the study was conducted on these patients who were often written off as dead patients with a haematocrit value of $\geq 20 \%$ in retroviral disease. Blood transfusion should be avoided in them while the treatment of opportunistic infections, nutritional optimization, deworming the patients, haematinics and preventing or reducing conditions that promote active bleeding in them. It is also a known fact that levamisole has immune-protective property with the antihelminthic effect. This informed the routine use of levamisole in this treatment. The nutritional intake of people living with HIV-AIDS in rural communities was accessed through a 72- hour diet recall which was low in micronutrients particularly of vitamin B complex group. The study concluded that provision of food rich in micronutrients is very important in treating HIV -patients and preventing opportunistic infections. [1Iyewellen,2004]. Transfusion-free surgery, which is better known to the public as bloodless surgery, can only be achieved by the application of blood management techniques to reduce allogenic transfusion. The three pillars of blood conservation must be enforced, namely: (1) Build up the patient's own blood, (2) Reduce blood loss and (3) Recycle the patient's own blood.

A study conducted by Ferri [] showed a reduction or elimination of blood transfusion which led to improved patient outcome. Many studies document increase morbidity and mortality after transfusion.[14] In a study of 1915 patients, those who received a blood transfusion had twice the 5-year mortality rate of those who did not. Even after correcting the comorbidities, age, and other factors, there was still a 70\% increase in mortality. [Ferri,2022; Levine, 2003], It was observed that optimizing anaemic patients presenting for elective surgery would prevent post-operative surgical site infections and their general wellbeing.[Bhaisara,2019;Bain,1999] 


\section{CONCLUSION}

Anaemia in human immunodeficiency virus or acquired immunodeficiency syndrome is a common presentation. The causes of the anaemia are multifactorial. Blood transfusion should be sparingly used in treating them as this practice does not increase their survival rate. The adopted protocol of treating them without transfusion but administering haematinics, antihelminthics, adequate balanced diet, treatment of opportunistic infections and observing blood conservation techniques should be instituted. The study concluded that bloodless management of severely anaemic HIV-patients with $\mathrm{PCV} \geq 20 \%$ without blood transfusion had higher survival rate than those who were transfused and should be encouraged Declaration of Interest: No conflict of interest.

Funding: No Financial Assistance was given by any group.

Limitations of the study: The study had small sample size and the assessment of anaemia was done only in patients of haematocrit values $\geq 20 \%$ Further research topic: A repeat of the study using a larger sample would help to improve the study.

\section{REFERENCE}

[1].Volberg PA, Levine AM, Dieterich D, Mildan D, Mitzsuyasu R, Saag M. Anaemia in HIV infection : Clinical Impact and Evidenced -Based Management Strategies. Clinical Infect. Dis. 2004; 38(10)1454-1463.

[2].Hebert PC, Wells G, Blacjchman MA, et al. A multicenter, Randomized, Controlled Clinical Trial of Transfusion Requirements in Critical Care. Transfusion requirements in clinical care investigators, Canadian critical care trial Group. N Engl Med. 1999; 340:409-417.

[3].Blumberg N, Heal JM. Effects of transfusion on immune function. Cancer Recurrence and Infection. Archpathol. Lab. Med. 1994; 118:371-379.

[4].Lum E. Kimbi H, Onyoh E. Bessong P.et al. The Impact of HIV and Plasmodium Falciparium genetic Diversity on anaemia in HIV - patients Attending Care and Treatment Centre at Baptist Hospital, Mutengene . International Journal of Research Studies in Bioscience.2016; 4(5): 26-37.

[5].Bhusal RR, Devkota S, Shrestha M, Khadga P. Profile of Anaemia in HIV Positive Patients. JCMS Nepal. 2016,12(2):70-73.

[6].Ford P, Mastoris J, Badani K, Columbus M. Profitability of Medical Procedures without the use of Transfusion Support. Blood. 2004; 104:5316.

[7].Engoren MC, Habib RH, Zacharias A, Schwan TA, Riordan CJ, Durham SJ. Effect of Blood Transfusion on Longterm Survival after Cardiac Operation. Ann. Thorac Surg. 2002; 74:1180-1186.

[8].Claster S. Biology of Anaemia , Different Diagnosis and Treatment Options in Human Immunodeficiency Virus Infection. J. infect. Dis. 2002;185(2): 5105-5109.

[9].Sullivan P. Association of Anaemia, Treatments for Anaemia, and Survival in Patients with Human Immunodeficiency Virus Infection. J. Infect. Dis.2002; 185(2):138-142.

[10]. Volberding P. The impact of anaemia on Quality of life in Human Immunodeficiency Virus - infected Patients. J. Infect. Dis.2002;185(2):5110-4

[11]. Akiwu U. Nutritional Intake of People Living with HIV/AIDS in Rural Communities of Benue State, Nigeria. Journal of Agriculture and food sciences. 2018; 16(2):88-99.

[12]. Llewellyn CA, Heritt PE, Knight RS, et al .Possible Transfusion of Variant CreutzfeldtJacob blood Transfusion. Lancet. 2004:363:417-412.

[13]. Ferri RS, Adinolfia A, Orsi DJ, Keruly JC, Davis S, Machtyre RC. Treatment of Anaemia in Patients with HIVinfection ..Part 2:Guidelines for management of Anaemia. J. Assoc. Nurses AIDS . 2002;13(1):50-59.

[14]. Levine BJ. Anaemia in the Setting of Cancer and Human Immunodeficiency Virus. Clin. Infect. Dis.2003;37(4):5304-5314

[15]. Bhaisara BB, Gaire M, Manglani M, Wade M, Shorma S. Impact of Anaemia on Outcome of HIV Infected Paediatric Patients: A Prospective Observational Study. Indian J. Community Medicine. 2019; 44(2):152-156.

[16]. Bain BJ. Pathogenesis and Pathophysiology in HIV Infection. Curr Open Haematol. 1999;6(2):89-93. 